\title{
Incidence of Bedsore among the admitted Patients in a Tertiary Care Hospital
}

\author{
${ }^{1}$ Sukhpal Kaur, ${ }^{2}$ Amarjeet Singh, ${ }^{3}$ Mandeep S Dhillon, ${ }^{4}$ Manoj K Tewari, ${ }^{5}$ Parabjyot Kaur Sekhon
}

\section{ABSTRACT}

Background and objective: Bedsore is a disruptive and often disabling condition affecting bedridden, infirm, debilitated and malnourished patients. We looked at the incidence of bedsores among the admitted patients in a tertiary care hospital.

Materials and methods: This was an observational cohort study covering 2408 patients. The patients were followed up every alternative day from the day of admission till their discharge/ death from the hospital. Katz index of independence in activities of daily living was used to evaluate the level of functional dependence of patients. Braden scale was used to assess the risk factors for the formation of bedsores.

Results: A pooled incidence of $5.9 \%$ was estimated. The incidence of bedsore was maximum in intensive care units $(9.4 \%)$, followed by orthopedic units $(8 \%)$, emergency wards $(7.7 \%)$ and neurosurgical units (6\%). Mean age was $44.6 \pm$ 17.56 (14-90 years). Unconscious patients, those admitted through emergency, and those who stayed longer in emergency and on IV fluids had a significantly higher chance of developing bedsores. This was also true for patients on Jejunostomy/Gastrostomy feed or total parenteral nutrition (TPN); who needed elevation of the head end of the bed; for whom assistance was required to change their position; and the patients whose position was changed less frequently $(p<0.05)$. The sacrum was the most common site for all the four stages of bedsores.

Conclusion: A bedsore incidence of $6 \%$ mandates an urgent need to improve the quality of patient care in various units of the hospital. Appropriate equipment, adequate manpower and administrative concern and accountability is the need of the hour.

Keywords: Bedsores, Admitted patients, Incidence.

How to cite this article: Kaur S, Singh A, Dhillon MS, Tewari MK, Sekhon PK. Incidence of Bedsore among the Admitted Patients in a Tertiary Care Hospital. J Postgrad Med Edu Res 2015;49(1):26-31.

\footnotetext{
${ }^{1}$ Lecturer, ${ }^{2-4}$ Professor, ${ }^{5}$ Senior Research Fellow

${ }^{1,5}$ National Institute of Nursing Education, Postgraduate Institute of Medical Education and Research, Chandigarh, India

${ }^{2}$ School of Public Health, Postgraduate Institute of Medical Education and Research, Chandigarh, India

${ }^{3}$ Department of Orthopedics, Postgraduate Institute of Medical Education and Research, Chandigarh, India

${ }^{4}$ Department of Neurosurgery, Postgraduate Institute of Medical Education and Research, Chandigarh, India

Corresponding Author: Sukhpal Kaur, Lecturer, National Institute of Nursing Education, Postgraduate Institute of Medical Education and Research, Chandigarh, India, Phone: 09888536964, e-mail: sukhpal.trehan@yahoo.in
}

Source of support: Nil

Conflict of interest: None

\section{INTRODUCTION}

Bedsores are a serious health issue for patients in all the kinds of settings. Incidence of bedsore varies from 0.4 to $38.0 \%$ in major hospitals, 2.2 to $23.9 \%$ in those on long-term care and 0 to $17 \%$ in home care settings. ${ }^{1-4}$ Bedsores are associated with prolonged and expensive hospitalization.

Various risk factors for bedsores can be categorized as intrinsic and extrinsic factors. The intrinsic risk factors include limited mobility, comorbidites, such as diabetes, chronic obstructive pulmonary disease, congestive heart failure, malignancy and renal dysfunction, poor nutrition and aging skin. Extrinsic factors include: pressure, friction, shear and moisture. ${ }^{5}$ Shear forces cause stretching and angulation of blood vessels; these are generated when the head of the bed is elevated and the person slides toward the foot end of the bed. Among the extrinsic factors, excessive compression of the soft tissues between a bony prominence and the surface of the bed is well known. A standard hospital mattress can generate pressure of 45 to $75 \mathrm{~mm} \mathrm{Hg}$. ${ }^{6}$ Pressure of $200 \mathrm{~mm} \mathrm{Hg}$ for 16 hours or $600 \mathrm{~mm} \mathrm{Hg}$ for 11 hours are required before a fullthickness injury occurs. ${ }^{7}$

Pressure ulcers are usually located over bony prominences. Majority $(80 \%)$ of bedsores occur over the heels, lateral malleoli, sacrum, ischia and greater trochanters. ${ }^{7}$ Prevention of pressure ulcers can lead to a reduction in the suffering, morbidity, bed occupancy, work load and the cost of healthcare. It is a great nursing care challenge and a thorough understanding of the etiological factors is required. Extent and duration of immobility affects the incidence of bedsore development and regular repositioning has been shown to significantly decrease pressure ulcer development. ${ }^{8}$ A written schedule should be used to direct and document repositioning the position and position of bedbound patients should be changed two hourly. Thirty degree oblique position has been shown to be the ideal position for bedridden patients. ${ }^{9}$ Specialized support surfaces (mattresses and beds) have also been shown to decrease the incidence of bedsores. ${ }^{10-12}$

Keeping all these factors in mind, the current study was carried out to estimate the incidence of bedsore in 
the admitted patients of PGIMER, Chandigarh and to see if the incidence is different from the published literature.

\section{METHODOLOGY}

The study was carried out in medical ward, surgical ward, advanced trauma centre, orthopedic ward, neuro medicine and surgical ward, main ICU and other intensive care units of the hospital. This was an observational cohort study. All the patients admitted during the study period (i.e. 2 months in each unit) were assessed for the development of bedsore. Patient information proforma was used to collect the data regarding the demographic characteristics of the subjects. Katz index of independence in activities of daily living (ADL) ${ }^{13}$ was used to evaluate the level of functional dependence of patients, viz. bathing, dressing, toileting, transferring, continence and feeding. Maximum attainable score for all the activities was six. For each activity score one meant that the patient was independent in carrying out each activity and score zero meant that the patient was totally dependent for the concerned activity. Braden scale ${ }^{14}$ was used to assess the risk factors for the formation of bedsores. It involves assessment of the patient on six parameters, i.e. sensory perception, moisture, activity, mobility, nutrition, and friction and shear. The maximum attainable score was 23 and the minimum score was six. The patient was considered to be at 'risk' of developing bedsore if the score was between 15 and 18, at 'moderate risk' if the score was 13 to 14 , at 'high risk' if the score was 10 to 12 and at 'very high risk' if the score was nine or less. Site assessment check list was used to evaluate the site for the development of bedsore. Pressure ulcer staging scale was used to categorize the bedsores as per the stage.

All the patients were followed up till their discharge from the hospital. Each patient was visited on alternate days to document the development of bedsore. Bedsore care practices adopted in the hospital were ascertained among the cases that developed bedsores. New cases were recruited in the study as and when they were admitted in the units under study.

Clearance was obtained from the Institute Ethics Committee. Written permission was obtained from concerned authority of each unit. Informed verbal consent was sought from the patients/care givers. The data were analyzed using SPSS-16 package. Both descriptive and inferential statistics were employed.

\section{RESULTS}

\section{Pooled Incidence of Bedsores}

Out of the total enrolled patients, 141 (5.9\%) developed bedsore during the observation period (Fig. 1).
More patients from intensive care units developed bedsore $(9.4 \%)$ as compared to others. The next highest incidence was in patients admitted in the orthopedic units, emergency wards and neurosurgical units. Least percentage of bedsores was noted from the medical and surgical wards (Table 1).

\section{Sociodemographic Profile of the Patients}

As depicted in Table 2, mean age \pm SD of the subjects who developed bedsore was $44.6 \pm 17.56$ with the range of 14 to 90 years. Around one-fifth (21.4\%) of the subjects were above 60 years of age. As per age, gender, marital status, and educational status, there was no significant difference in the development of bedsore. Occupation wise, there were significantly more number of patients who were not working or who were involved in petty businesses like driver, social worker, cycle-repair, milkman, and tailor $(\mathrm{p}<0.05)$.

\section{Clinical Data of the Patients}

The incidence of bedsore was higher in thin built patients and those who were overweight, but the difference was not statistically significant. However, there were significantly more patients who were unconscious, were admitted through emergency department and stayed for more days in emergency, or who were on IV fluids, on Jejunostomy/Gastrostomy feed or total parenteral nutrition $(\mathrm{TPN})$ who developed bedsores $(\mathrm{p}<0.05)$ (Table 3).

\section{Assessment of Dependency Level and Risk Assessment of Bedsore among the Patients}

As per Katz score, majority of the patients $(83 \%)$ who developed bedsore were completely dependent for all of their activities of daily living, i.e. bathing, dressing, going to the toilet, transferring, continence, and feeding. As per Braden scale, $34.8 \%$ patients were at 'very high risk', $38.3 \%$

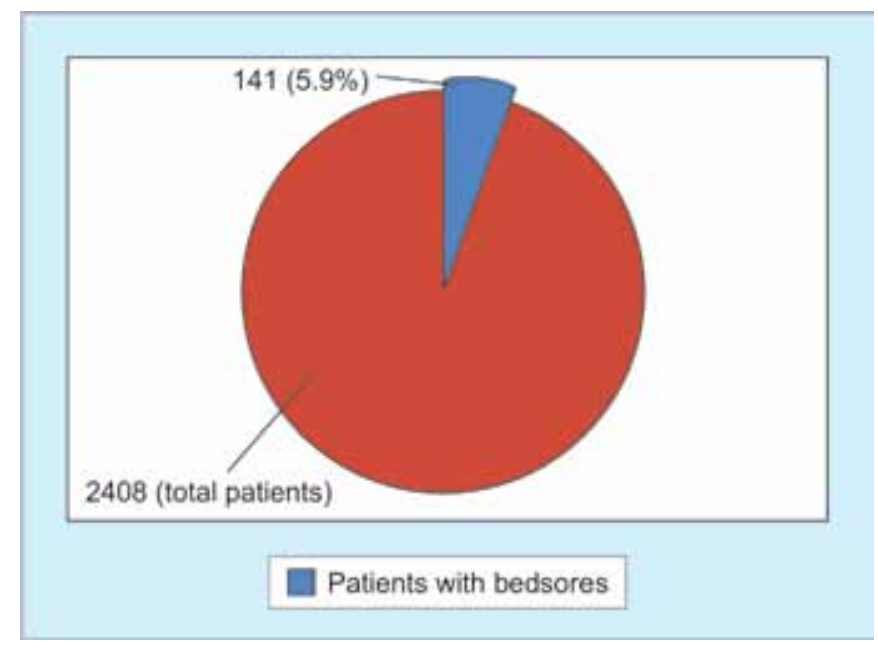

Fig. 1: Incidence of bedsores 
were at 'high risk', 15\% were at 'moderate risk' and 23\% were at 'risk' of development of bedsore.

\section{Variables related to Positioning of the Patients}

Table 4 shows the variables related to positioning the patients in the bed. There was significantly higher incidence of bedsore in patients who needed elevation of the head end of the bed, for whom assistance was required to change their position, and patients whose position was changed less frequently $(\mathrm{p}<0.05)$.

\section{Common Sites and Stages of Bedsores}

Figure 2 shows the stages of bedsores and the anatomical site involved. Sacrum was the commonest site for all the four stages of bedsores. It was followed by bedsore at ilium and heels.

\section{DISCUSSION}

Bedsores are a potential problem in intensive care patients. It is a known fact that the patients in critical care units are quite sick. Most of them are unconscious

Table 1: Incidence of bedsore as per the wards/units

\begin{tabular}{|c|c|c|c|c|}
\hline & Frequency & Bedsores & & \\
\hline Wards & $\begin{array}{l}\text { Total no. of patients recruited } \\
(N=2408) n(\%)\end{array}$ & $\begin{array}{l}\text { Proportion of patients who developed } \\
\text { bedsores }(N=141) n(\%)\end{array}$ & $\chi^{2}(d f)$ & $p$-value \\
\hline Medical wards & $889(36.9)$ & $41(4.6)$ & $23.55(5)$ & 0.03 \\
\hline Surgical wards & $612(25.4)$ & $28(4.6)$ & & \\
\hline Neurosurgery & $131(5.4)$ & $08(6.1)$ & & \\
\hline Emergency & $300(12.5)$ & $23(7.7)$ & & \\
\hline Orthopedics & $273(11.3)$ & $22(8.1)$ & & \\
\hline Intensive care units & $203(8.4)$ & $19(9.4)$ & & \\
\hline
\end{tabular}

df: Degrees of freedom

Table 2: Sociodemographic profile of the patients

\begin{tabular}{|c|c|c|c|c|}
\hline Variables & $\begin{array}{l}\text { Frequency } \\
\text { Total no. of patients recruited } \\
(N=2408) n(\%)\end{array}$ & $\begin{array}{l}\text { Bedsores } \\
\text { Patients who developed } \\
\text { bedsores }(N=141) n(\%)\end{array}$ & $\chi^{2}(d f)$ & $p$-value \\
\hline \multicolumn{5}{|l|}{ Age (years) } \\
\hline$\leq 20$ & $326(13.5)$ & $13(3.9)$ & $7.66(4)$ & $0.10(>0.05)$ \\
\hline $21-40$ & $940(39.1)$ & $49(5.2)$ & & \\
\hline $41-60$ & $812(33.6)$ & $56(6.8)$ & & \\
\hline $61-80$ & $310(12.8)$ & $20(6.4)$ & & \\
\hline \multirow[t]{4}{*}{81 and above } & $020(0.8)$ & $03(15)$ & & \\
\hline & Mean age \pm S.D: & Mean age \pm S.D: & & \\
\hline & $40.53 \pm 17.39$ & $44.6 \pm 17.56$ & & \\
\hline & Range: 2-93 years & Range: $14-90$ years & & \\
\hline \multicolumn{5}{|l|}{ Gender } \\
\hline Male & $1527(63.4)$ & $88(5.8)$ & $0.07(1)$ & $0.7(>0.05)$ \\
\hline Female & $881(36.6)$ & $53(6)$ & & \\
\hline \multicolumn{5}{|l|}{ Marital status } \\
\hline Ever married & $1846(76.6)$ & $116(6.2)$ & $6.77(1)$ & $0.1(>0.05)$ \\
\hline Unmarried & $562(23.3)$ & $025(4.4)$ & & \\
\hline \multicolumn{5}{|l|}{ Educational status } \\
\hline Primary or below & $831(34.5)$ & $53(6.3)$ & $8.24(2)$ & $0.31(>0.05)$ \\
\hline Senior secondary or below & $1203(49.1)$ & $68(5.6)$ & & \\
\hline Graduate and above & $374(15.5)$ & $20(5.3)$ & & \\
\hline \multicolumn{5}{|l|}{ Occupation } \\
\hline Not working* & $773(32.1)$ & $51(6.5)$ & $21.13(6)$ & $0.04(<0.05)$ \\
\hline Service & $650(26.9)$ & $42(6.4)$ & & \\
\hline Student & $306(12.7)$ & $12(3.9)$ & & \\
\hline Laborer & $269(11.2)$ & $14(5.2)$ & & \\
\hline Agriculture & 207 (8.6) & $12(5.7)$ & & \\
\hline Business & $164(6.8)$ & $07(4.2)$ & & \\
\hline Others ${ }^{* *}$ & $040(1.7)$ & $03(7.5)$ & & \\
\hline
\end{tabular}

*Housewife/retired, ${ }^{* *}$ driver, social worker, cycle repair, milkman and tailor, df: degrees of freedom; SD: standard deviation 
Table 3: Clinical data of the patients

\begin{tabular}{|c|c|c|c|c|}
\hline Variables & $\begin{array}{l}\text { Frequency } \\
\text { Total no. of patients recruited } \\
(N=2408) n(\%)\end{array}$ & $\begin{array}{l}\text { Bedsores } \\
\text { Patients who developed } \\
\text { bedsores }(N=141) n(\%)\end{array}$ & $\chi^{2}(d f)$ & p-value \\
\hline \multicolumn{5}{|l|}{ Body built } \\
\hline Normal & $2297(95.4)$ & $129(5.6)$ & $5.41(2)$ & $0.067(>0.05)$ \\
\hline Thin & $61(2.5)$ & $6(9.8)$ & & \\
\hline Overweight & $50(2.1)$ & $6(12)$ & & \\
\hline \multicolumn{5}{|l|}{ General condition } \\
\hline Conscious & $2031(84.3)$ & $91(4.9)$ & $59.11(2)$ & $0(<0.05)$ \\
\hline Unconscious & $264(11.0)$ & $43(16.2)$ & & \\
\hline Semiconscious & $113(4.7)$ & $7(6.2)$ & & \\
\hline \multicolumn{5}{|l|}{ Admission through } \\
\hline Emergency department & $1478(61.4)$ & $118(7.9)$ & $31.45(1)$ & $0(<0.05)$ \\
\hline General OPD & $930(38.6)$ & $23(2.4)$ & & \\
\hline \multicolumn{5}{|l|}{ Stay in emergency } \\
\hline$\leq 10$ & $1425(59.2)$ & $109(7.6)$ & $21.61(3)$ & $0(<0.05)$ \\
\hline $11-20$ & $43(1.7)$ & $5(11.6)$ & & \\
\hline $21-30$ & $9(0.3)$ & $4(44.4)$ & & \\
\hline More than 30 days & $1(0.04)$ & 0 & & \\
\hline \multicolumn{5}{|l|}{ Present diet } \\
\hline Normal & $1574(65.4)$ & $53(3.4)$ & $64.87(8)$ & $0(<0.05)$ \\
\hline NPO-IV fluid & $572(23.7)$ & $67(11.7)$ & & \\
\hline Diabetic diet & $108(4.4)$ & $9(8.3)$ & & \\
\hline Burn diet & $17(0.7)$ & 0 & & \\
\hline Renal diet & $62(2.5)$ & $2(3.2)$ & & \\
\hline High protein diet & $40(1.7)$ & $2(5)$ & & \\
\hline Jejunostomy/gastrostomy feed & $24(0.9)$ & $3(12.5)$ & & \\
\hline Total parenteral nutrition & $11(0.4)$ & $3(27.2)$ & & \\
\hline \multicolumn{5}{|l|}{ Type of mattresses } \\
\hline Mattress with rexine cover & $2202(91.5)$ & $78(3.5)$ & & \\
\hline Alternating air mattresses & $206(8.5)$ & $63(30.6)$ & $249.8(1)$ & $0(<0.05)$ \\
\hline
\end{tabular}

Table 4: Variables related to positioning of the patients

\begin{tabular}{|c|c|c|c|c|}
\hline Variables & $\begin{array}{l}\text { Frequency } \\
\text { Total no. of patients recruited } \\
(N=2408) n(\%)\end{array}$ & $\begin{array}{l}\text { Bedsores } \\
\text { Patients who developed } \\
\text { bedsores }(N=141) n(\%)\end{array}$ & $\chi^{2} d f$ & $p$-value \\
\hline \multicolumn{5}{|c|}{ Patients needing head elevation } \\
\hline No & $1684(69.9)$ & $65(3.8)$ & $40.49(1)$ & $0(<0.05)$ \\
\hline Yes & $724(30.1)$ & $76(10.5)$ & & \\
\hline \multicolumn{5}{|c|}{ Repositioning the patient by } \\
\hline Lifting & $2396(99.4)$ & $140(5.8)$ & $0.13(1)$ & $0.714(>0.05)$ \\
\hline Dragging & $12(0.5)$ & $1(8.3)$ & & \\
\hline \multicolumn{5}{|c|}{ Position change done by } \\
\hline Self & $1673(69.4)$ & $35(2.1)$ & $1.41(1)$ & $0(<0.05)$ \\
\hline Assisted & $735(30.5)$ & $106(14.4)$ & & \\
\hline \multicolumn{5}{|c|}{ Frequency of position change } \\
\hline Ambulatory & $1501(62.3)$ & $30(2.0)$ & $1.23(5)$ & $0(<0.05)$ \\
\hline Less than hourly & $224(9.3)$ & $19(8.5)$ & & \\
\hline Every 2 hourly & $222(9.2)$ & $39(17.6)$ & & \\
\hline 2-4 hourly & $58(2.4)$ & $7(12.1)$ & & \\
\hline 4-6 hourly & $80(3.3)$ & $12(15)$ & & \\
\hline$>6$ hourly & $323(13.4)$ & $34(10.5)$ & & \\
\hline
\end{tabular}




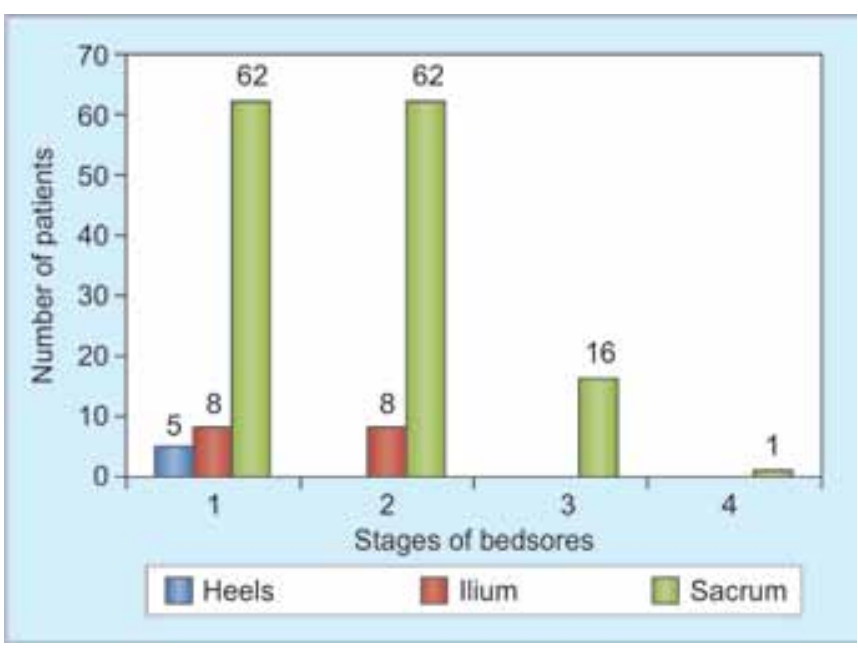

Fig. 2: Stages of bedsores with sites involved

and totally dependent upon the health care professional. A large proportion of the patients are immune compromised. High prevalence $(41 \%)^{13}$ and incidence $(33 \%)^{14}$ of bedsore has been reported from other countries. Even rates of greater than $50 \%$ have also been reported for patients in intensive care settings. ${ }^{15}$ Pooled incidence of bedsore in the current study was $6 \%$. The majority of the patients who developed bedsore were from intensive care units $(9.4 \%)$.

The incidence of bedsore in patients admitted in emergency department was also high. Most (8\%) patients in other units who developed bedsore had also been admitted through emergency. This could be explained by the fact that most of the patients remain lying on the stretchers in emergency for hours together which increases the risk for bedsore development among the patients. A high proportion of patients admitted through the emergency department were at risk for pressure ulcer development, as has also been reported by Tarpey et al. ${ }^{12}$

Shear forces are generated when the head of the bed is elevated and the person slides toward the foot of the bed. Similarly friction occurs, if the patient is dragged instead of being lifted while repositioning. There were significantly more number of patients $(10.5 \%)$ who needed elevation of the head end of the bed, for whom assistance was required to change their position, and the patients whose position was changed less frequently. It is usually recommended that in hospital care the immobile patients should be repositioned every 2 hours. ${ }^{16}$ However, in around one-fourth of the subjects in the current study, the frequency of change of position was more than four hourly, implying suboptimal care being given.

It has been reported that the use of alternating-air mattress or a water bed lower the incidence of pressure ulcers by more than half among the hospitalized patients. ${ }^{17}$ However, in the present study, it was noticed that only $31 \%$ patients were provided alternating air mattresses. Thus, a majority of patients were at further risk to develop the bedsore.

Age is considered as a significant risk factor for the development of bedsore. Elderly are more prone for bedsore; $21.4 \%$ of the subjects in the present study were above 60 years of age. Bedsore development is directly linked to tolerance of tissues for pressure as well as the intensity and duration of that pressure. With increase in age, the skin elasticity is reduced, the skin become more fragile, and is likely to get damage even with less duration of pressure.

One fact to note is that if at the time of admission in the hospital, all the patients are assessed for the risk of development of bedsore, the incidence of bedsore can be reduced. ${ }^{18}$ In the current study, as per the Braden scale, all the patients with bedsore were at various levels of risks, i.e. very high risk, high risk, moderate risk and at risk of development of bedsore and majority were dependent for all the activities of daily life, i.e. bathing, dressing, toileting, transferring, continence, and feeding as per the score of Katz index. A policy regarding the use of these types of scales needs to be formulated before implementing it in the clinical situations. Nevertheless it is important that the nurses are made aware regarding the use of these scales for improving the quality of care.

Several studies reveal varying sites which commonly are involved in occurrence of bedsores. ${ }^{8,19-24}$ In the current study, sacral area was the commonest site for the four stages of bedsores. Supine position is the most favored position for the bedridden patients. Also these areas are more likely to remain wet because of urinary and fecal incontinence superadded with contamination with various microorganisms.

The incidence of bedsore in the orthopedic and neurosurgical patients in the present study was quite high. The possible reason for the higher incidence of bedsore in these patients may be that majority of these patients remain immobile for a number of days. Even neurosurgery patients remain in altered sensorium for long-time postoperatively. Lack of frequent posture change due to these conditions is a known causative factor of bedsore. ${ }^{25}$

This study had several strengths. The sample size was large and we did not rely on hospital nurses for any data. A direct assessment of the probable sites of bedsore development was performed by specially trained research personnel. It has been documented that using retrospective record review as the source of information may significantly underestimate pressure ulcer incidence. ${ }^{26}$ 
The limitation of the study was that data in each unit under study was collected only for 2 months. The factors influencing the development of bedsores were not studied.

\section{CONCLUSION}

An overall incidence of $6 \%$ of bedsore in a tertiary care hospital is a matter of concern for the healthcare administrators. Appropriate monitoring of the patients needs to be performed to lower the incidence. There is a need to develop strategies for reduction and prevention of bedsores in hospital. The pooled incidence data may provide a benchmark to evaluate the preventive strategies for the bedsore.

\section{CLINICAL IMPLICATIONS}

Periodical sessions should be carried out to sensitize the nurses regarding prevention and management of bedsores in all the units. An interdisciplinary, collaborative approach is required, and healthcare providers should develop an understanding that prevention of bedsore is a team goal that requires a team effort. The nurses should provide and document ongoing skin assessments, develop individualized plans of care, and implement evidence-based strategies for the prevention of bedsores. This would ideally evolve from well supervised quality control checks for nursing care.

\section{ACKNOWLEDGMENTS}

The financial assistance provided by the PGI research scheme (vide grant no. 71/2-Edu/09/442) is acknowledged. Authors acknowledge the co-operation of all the unit heads. Authors also wish to thank patients and their families for their willingness to participate in the study.

\section{REFERENCES}

1. Lyder $\mathrm{CH}$. Pressure ulcer prevention and management. JAMA 2003;289(2):223-226.

2. Reddy M, Gill SS, Rochon PA. Preventing pressure ulcers: a systematic review. JAMA 2006;296(8):974-984.

3. Cuddigan J, Berlowitz DR, Ayello EA. Pressure ulcers in America: prevalence, incidence, and implications for future. An executive summary of the national pressure ulcer advisory panel monogrph. Adv Skin Wound Care 2001;14(4):208-215.

4. Garcia AD, Thomas DR. Assessment and management of chronic pressure ulcers in the elderly. Med Clin North Am 2006 Sep;90(5):925-944.

5. Ven den Heede K, Clarke SP, Sermeus W, Vleugels A, Aiken LH. International experts' perspectives on the state of nurse staffing and patient outcomes literature. J Nursing Scholarship 2007;39(4):290-297.
6. Daniel RK, Priest DL, Wheatley DC. Etiological factors in pressure sores: an experimental model. Arch Phys Med Rehabil 1981 Oct;62(10):492-498.

7. Livesley NJ, Chow AW. Infected pressure ulcers in elderly individuals. Clin Infect Dis 2002 Dec 1;35(11):1390-1396.

8. Roberts BV, Goldstone LA. A survey of pressure sores in the over sixties on two orthopaedic wards. Int J Nurs Stud 1979;16(4):355-364.

9. Versluysen M. How elderly patients with femoral fracture develop pressure sores in hospital. Br Med J (Clin Res Ed) 1986 May 17;292(6531):1311-1313.

10. Robnett MK. The incidence of skin breakdown in a surgical intensive care unit. J Nurs Qual Assur 1986 Nov;1(1):77-81.

11. Bergstrom N, Demuth PJ, Braden BJ. A clinical trial of the braden scale for predicting pressure sore risk. Nurs Clin North Am 1987 Jun;22(2):417-428.

12. Tarpey A, Gould DJ, Fox C, Davies P, Cocking M. Evaluating support surfaces for patients in transit through the accident and emergency department. J Clin Nurs 2000 Mar;9(2):189-198.

13. Katz S, Down TD, Cash HR, Grotz RC. Progress in the development of the index of ADL. Gerontologist 1970Spring;10(1):20-30.

14. Bergstrom N, Braden BJ, Jaguzza A, Holman V. The Braden scale for predicting pressure sore risk. Nurs Res 1987 JulyAug;36(4):205-210.

15. Jiricka MK, Ryan P, Carvalho MA, Bukvich J. Pressure ulcer risk factors in an ICU population. Am J Crit Care 1995 Sep; 4(5):361-367.

16. Reuler JB, Cooney TG. The pressure sores: pathophysiology and principles of management. Ann Intern Med 1981 May;94(5): 661-666.

17. Andersen KE, Jensen O, Kvorning SA, Bach E. Decubitus prophylaxis: a prospective trial of the efficiency of alternating-pressure air-mattresses and water-mattresses. Acta Derm Venereol 1982;63(3):227-230.

18. Moody BL, Fanale JE, Thompson N, Vaillancourt D, Symonds G, Bonasoro C. Impact of staff education of pressure ulcer development in elderly hospitalized patients. Arch Intern Med 1988 Oct;148(10):2241-2243.

19. National pressure ulcer advisory panel. Pressure ulcers: incidence, economics, risk assessment. Consensus development conference statement. West Dundee, Ill: SN Publications 1989.

20. Allman RM. Pressure ulcers among the elderly. N Engl J Med 1989 Mar;320(13):850-853.

21. Yarkony GM. Pressure ulcers: a review. Arch Phys Med Rehabil 1994 Aug;75(8):908-917.

22. Allman RM, Walker JM, Hart MK, Laprade CA, Noel LB, Smith CR. Air-fluidized beds or conventional therapy for pressure sores: a randomized trial. Ann Intern Med 1987 Nov;107(5):641-648.

23. Fuhrer MJ, Garber SL, Rintala DH, Clearman R, Hart KA. Pressure ulcers in community-resident persons with spinal cord injury: prevalence and risk factors. Arch Phys Med Rehabil 1993 Nov;74(11):1172-1177.

24. Garber SL, Campion LJ, Krouskop TA. Trochanteric pressure in spinal cord injury. Arch Phys Med Rehabil 1982 Nov; 63(11):549-552.

25. Cannon BC, Cannon JP. Management of pressure ulcers. Am J Health Syst Pharm 2004 Sep 15;61(18):1895-1907.

26. Knox E. Changing the records. Nurs Times 1998 Jun 17-23; 94(24):67-68. 